\title{
Exploration of Augmented Reality in Spatial Abilities Training: A Systematic Literature Review for the Last Decade
}

\author{
Christos PAPAKOSTAS, Christos TROUSSAS, Akrivi KROUSKA, \\ Cleo SGOUROPOULOU \\ Department of Informatics and Computer Engineering, University of West Attica, Greece \\ e-mail: \{cpapakostas, ctrouss, akrouska,csgouro\}@uniwa.gr
}

Received: May 2020

\begin{abstract}
This review paper presents a systematic literature review on the use of Augmented Reality (AR) in engineering education, and specifically in student's spatial ability training, for the last decade. Researchers have explored the benefits of AR, and its application has been of increasing interest in all levels of education. Engineering students tend to have difficulties in acquiring visualization skills, and hence, AR is gaining momentum in enhancing students' learning achievements. This paper aims to present valuable information to researchers, tutors and software developers of learning technology systems concerning the advantages and limitations of AR in spatial ability training, the incorporation of adaptivity and personalization in AR applications as well as the aspects of spatial ability having been evaluated using AR and the prevalent evaluation methods for AR applications. To this direction, a total of thirty-two (32) studies were reviewed, having been published since 2010 . The findings reveal an increase in the number of studies during the last three years. One major conclusion is the improvement of learners' spatial ability using $\mathrm{AR}$ in educational settings, and the noted challenge is the need for more learning content. One research gap that has been identified is the lack of personalization in the developed applications, offering space for future research. Concluding, this area is under-researched, and thus, there is scope for a lot of improvement.
\end{abstract}

Keywords: Augmented Reality, spatial ability, visualization skills, technical drawing, educational technology, literature review.

\section{Introduction}

In engineering education, the enhancement of the visualization skills of the students is essential for the development of the design skills in many fields of engineering (Ali et al., 2017b; Serdar et al., 2013). Engineering drawing is the first course offered to students in engineering faculties in order to provide the basics of engineering education. First year engineering students have difficulties in drawing orthographic views 


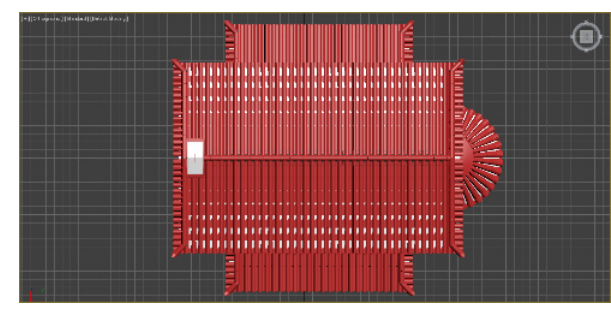

(a) Top view

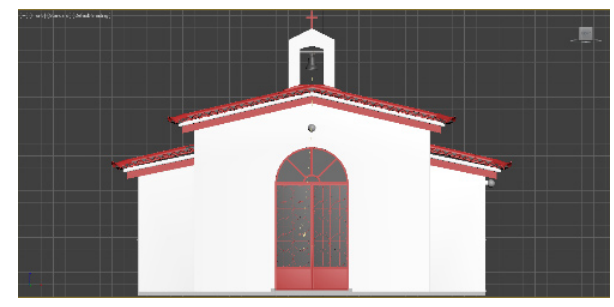

(c) Front view

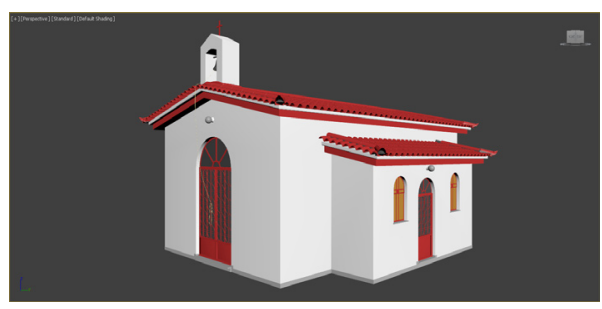

(b) $3 \mathrm{D}$ view

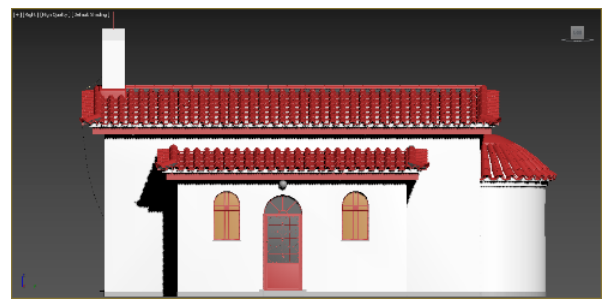

(d) Right side view

Fig. 1. Spatial orthographic projections (a, c, d) of a 3D construction (b).

and perspectives (an example is shown in Fig. 1), since they find it difficult to understand 3D shapes from 2D views (Arslan \& Dazkir, 2017; Figueiredo et al., 2014). Engineering drawing plays an important role towards the efforts in improving students' spatial ability.

Spatial ability may be defined as the ability to generate, retain, retrieve, and transform well-structured visual images. Spatial ability is not a unitary construct. There are, in fact, several spatial abilities, emphasizing different aspects of the process of image generation, storage, retrieval, and transformation. Spatial abilities are pivotal constructs of all models of human abilities (Lohman, 1996).

Engineering drawing was used to be taught using chalk and board, as well as model blocks back in the days. Nowadays, the development of technology has introduced the use of computer-aided software in the teaching of engineering drawing in higher institutions (Jian, 2011). Recent studies have shown that AR is considered to be one of the best alternative teaching approaches to cover these issues (Ali et al., 2017b; Huerta et al., 2019; Yilmaz, 2018).

AR provides an ideal interface to Internet of Things (IoT) applications by superimposing virtual information about smart objects and services on a user's view of the real world (White, Cabrera, Palade, \& Clarke, 2019). An AR system has the following properties:

- Combines real and virtual objects in a real environment.

- Runs interactively, and in real time.

- Registers (aligns) real and virtual objects with each other (Azuma et al., 2001).

AR has been implemented in engineering drawing classroom since recent years (Ali et al., 2017b). Many researchers have studied the advantages of this technology to improve students' performance in engineering drawing, as well as to train their spatial 
abilities or visualization skills that are critical for their studies and future career (Sorby, 2007). Engineering students need to have visualization skills to be able to master engineering courses.

There is a large volume of published studies that report the advantages, the limitations and the challenges of AR in education (Akçayır \& Akçayır, 2017; Karakus et al., 2019; Yilmaz, 2018). Various interactive and innovative applications generated by AR technology have given great potentials in different learning subjects and specifically in STEM (Science, Technology, Engineering, and Mathematics) education (Pellas \& Kazanidis, 2019).

While a great deal of prior review research has focused on developing spatial ability, few studies focus on the relationship between AR and spatial ability (Diao \& Shih, 2019; Voronina et al., 2019). In view of the above, this paper tackles the need for further research to collect and analyze data on this topic. To fill the gap in the literature, we conduct this research having the purpose to present a systematic literature review of AR used in training spatial ability since the last decade. The following research questions (RQs) are addressed:

RQ1: What are the advantages of AR in spatial ability training?

RQ2: What are the limitations of AR in spatial ability training?

RQ3: Has the incorporation of combined adaptivity or personalization techniques been considered in AR apps?

RQ4: Which specific aspects of spatial ability have been evaluated using AR?

RQ5: What are the evaluation methods considered for AR applications in educational scenarios?

\section{Relevant Literature}

A very recent study by Voronina et al. (2019) examined the use of AR in teaching students and future teachers of Descriptive Geometry, Engineering and Computer Graphics (DGECG). Their results showed that there is an absence of scientifically substantiated and proven programs and training materials for training students of DGECG using AR, needing further scientific research in this field. However, the study examined solely 9 articles without focusing on a detailed overview of the research in the area of enhancing spatial skills within AR environments; the authors mainly identified the indispensable need for comprehensive future research in the area of descriptive geometry.

Diao \& Shih (2019) conducted another systematic review of literature concerning AR in architectural and civil engineering education. Analysis was performed based on fundamental information, application domains, AR development tools, system types, teaching devices, teaching methods, learning strategies and research methods. The study focused on domain-specific studies of architects and civil engineers, and ignored crossdomain contributions. Additionally, the study lacks in the evaluation of the contribution of AR in spatial skills training.

While a great deal of prior reviews of AR applications have focused on the field of education (Garzón, Pavón, \& Baldiris, 2019), there is an absence of systematic litera- 
ture review on the use of AR in training spatial skills. According to Tuker (2018), very little or no systematic research work has been conducted studying the effects of VR/ AR systems in training spatial skills. Moreover, no commercial VR/AR applications have been developed for this training purpose either. Therefore, a review of research studies in spatial ability training using AR technology can suggest areas to which future research can be oriented.

\section{Method}

This literature review follows the guideline for systematic reviews, appropriate for software engineering researchers, proposed by Kitchenham (2004). There is a variety of review designs and existing guidelines intended to aid medical researchers. The purpose of a review of healthcare literature is to summarize the knowledge around a specific topic and support health professionals make decisions about a care issue. Kitchenham's guideline is based on a review of three existing medical guidelines and adapts them to the need of software engineering researchers. In particular, software engineering research has relatively little empirical research compared with the large quantities of research available on medical issues, and research methods used by software engineers are not as rigorous as those used by medical researchers. The guideline has been adapted to reflect the specific problems of software engineering research (Kitchenham \& Charters, 2007).

The guideline covers three phases of a systematic review: planning the review, conducting the review and reporting the review. It is at a relatively high level (Kitchenham, 2004).

- At the first phase of the planning of the review, a review protocol is developed. The protocol serves as a roadmap for the review and specifies the objectives, methods, and outcomes of primary interest of the systematic review. The purpose of having a protocol is to promote transparency of the methods. A protocol defines the search terms, inclusion and exclusion criteria and data that will be analyzed.

- At the second phase the review is conducted. Once the protocol has been developed, the review starts. This involves the finding of studies relating to the research questions and the study of their actual relevance. Then, inclusion and exclusion criteria are applied in order to narrow down the results. Data extraction forms are designed to collect all the information needed for each study and data synthesis is used to collate and summarize the results of the studies.

- The third phase of the review is very important as it communicates the results of the systematic literature review.

The three main phases of the literature review are shown in Fig. 2. The first two phases are analyzed in this section; whereas the third phase of Reporting the Review including the analysis of the results, discussion of the findings, trends and conclusions of the review, is presented in Section 4. 


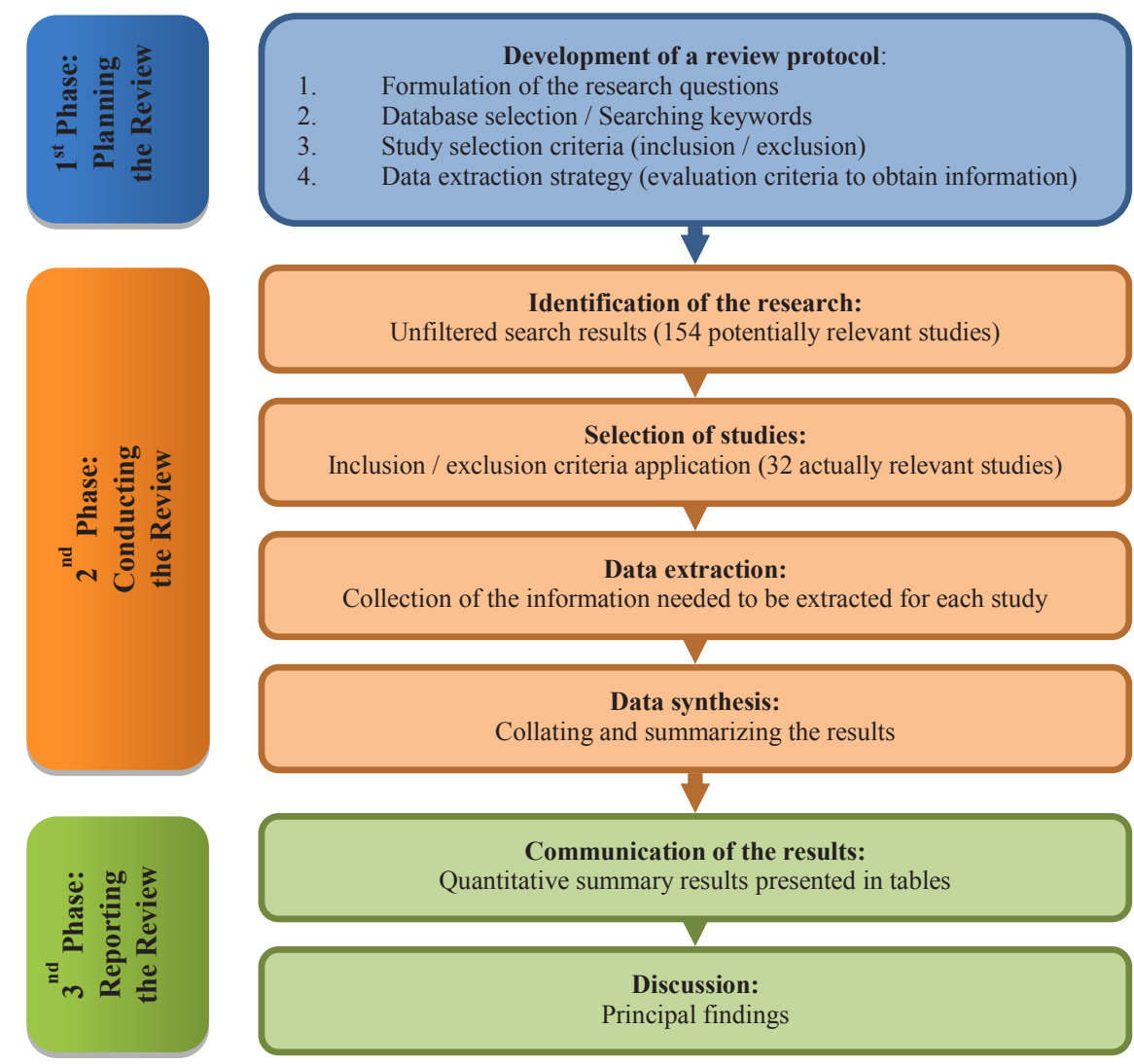

Fig. 2. Systematic literature review phases.

\subsection{Planning the Review (Review Protocol)}

For this review, we conducted a thorough search of scientific articles mainly in the Scopus database. The results were filtered through keywords in the paper title, abstract and keyword list. The search results discovered 154 papers, based on certain keywords "augmented reality" and "spatial ability" or "spatial skills", and "training" or "teaching" or "education".

Afterwards, we defined the inclusion and exclusion criteria. Considering the research questions, general criteria defining the time frame for the studies and the type of studies that are relevant were devised. The aim of this paper is to review the most recent literature regarding using AR in spatial abilities' training. The inclusion criteria were the time span of the last decade from 2010 to 2020 and the document language was determined as "English". Journal and/or conference literature review papers, Master or $\mathrm{PhD}$ theses were excluded from the systematic review. Papers that were not directly related to AR and spatial abilities' training were also determined as exclusion criteria. 
Table 1

Evaluation Criteria

\begin{tabular}{ll}
\hline Research Question & Evaluation Criteria \\
\hline RQ 1 & AR advantages \\
RQ 2 & AR limitations \\
RQ 3 & Learning tool \\
& AR approach \\
& AR type \\
& Software \\
& Type of adaptation process \\
RQ 4 & Spatial abilities Aspects \\
& Test used \\
RQ 5 & Research sample \\
& Research method \\
& Data collection method \\
\hline
\end{tabular}

In the final step of the first phase, we defined a group of analysis categories with their corresponding sub-categories according to each research question. These categories constitute the evaluation criteria used in the data extraction forms for each selected study. They also helped us in grouping studies according to their shared characteristics (Bacca et al., 2014). The list of evaluation criteria for the data extraction classified by the research questions is showed in Table 1.

\subsection{Conducting the Review}

All of the 154 papers from the first phase were thoroughly examined to determine their relevance to the study. Given their unsuitability for the purposes of this study, 122 papers were excluded due to the exclusion criteria and a total of 32 papers were included and were in the final analysis list. Twenty-one of the results are journal articles, eight of the results are conference papers and three of the results are books or book chapters.

All of the studies were evaluated and analyzed according to the research questions. We developed an article review form as a data collection tool to examine the articles to be reviewed. The data collection tool, developed by Goktas et al. (2012), was revised according to the research questions in the present study and was implemented as a table matrix in Microsoft Excel. It is composed of six sections, one section for the screening of the evaluation papers including article's general information and five more sections, one for each research question (Appendix A).

Each one of the 32 studies was thoroughly reviewed in order to determine the advantages and the limitations of the first and second research questions (RQ1 \& RQ2). Advantages were arranged into three categories: learner outcomes, pedagogical contributions and technical perspectives. Every article included more than one advantages and/or limitations was separately recorded. 


\subsubsection{Screening of the Evaluation Papers}

The first section of the data extraction form addresses the publication year, the target group, the level of education and the country. The year is the date of the publication of the journal or the conference and has a value from 2010 to 2020 . The level of education was divided into seven sub-categories of participants: preschool students, primary education students, secondary education students, technical education students, higher education students, teachers (of any level of education) and not specified (the learner type was not clearly specified).

The 32 publications on AR in spatial abilities' training were analyzed to determine the position of the subject in academia. Fig. 3 shows the number of studies according to their publication year. The first seven years of the time span (2010-2016) present a low number of studies (one or two studies per year). In 2017, it appears that the subject began to gain attention, with the number of publications up from one to seven over the previous year. Since 2017, at least six papers have been published each year. During the past three years (2017-2019), the average of publications per year was seven. This suggests that the research interest in AR and its implementation in spatial abilities' training has been increasing since 2017 and a similar level of interest will continue in 2020 and after. This finding is significant since it presents the value of this study to guide future studies in the field.

The countries that explored the application of AR in educational research are recorded and the major contributing countries in the studies are Malaysia, the United States of America (USA), Spain and Taiwan (Fig. 4). Three studies (Omar, Ali, Mokhtar, et al., 2019; Omar, Ali, Nasir, \& Sunar, 2019; Phon et al., 2019) of the leading contributing country, Malaysia, are conducted due to scholarships. More specific, Universiti Teknologi Malaysia, Universiti Malaysia Pahang, Universiti Tun Hussein Onn and the Ministry of Higher Education (MOHE) Malaysia provided the funds to support the researchers. Two studies (Serdar, Aziz, Esche, \& Chassapis, 2013; Tumkor, 2018) of the second

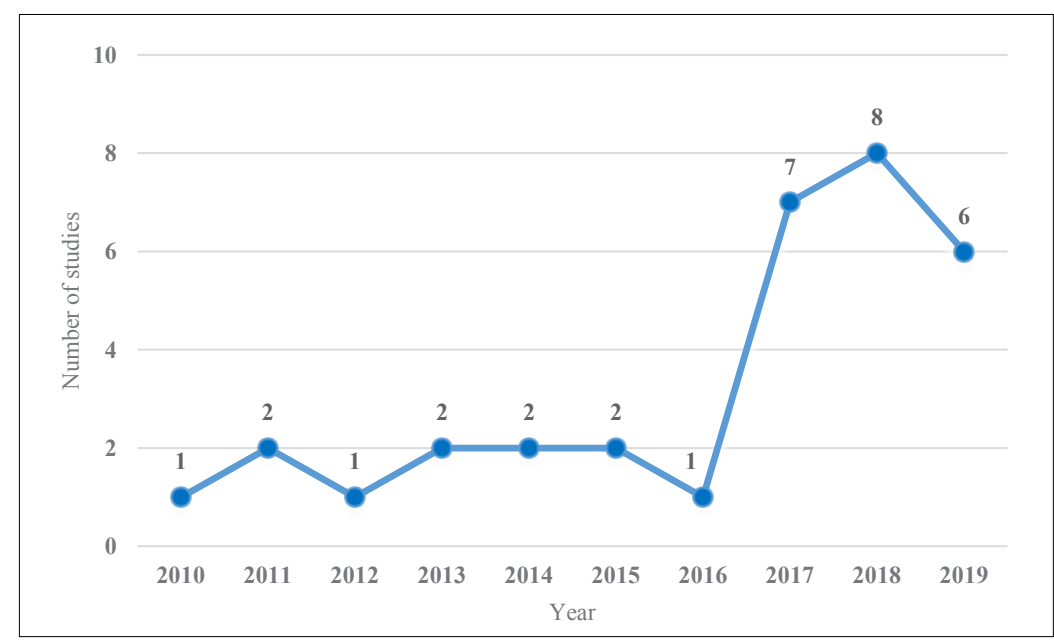

Fig. 3. The number of studies published by year. 


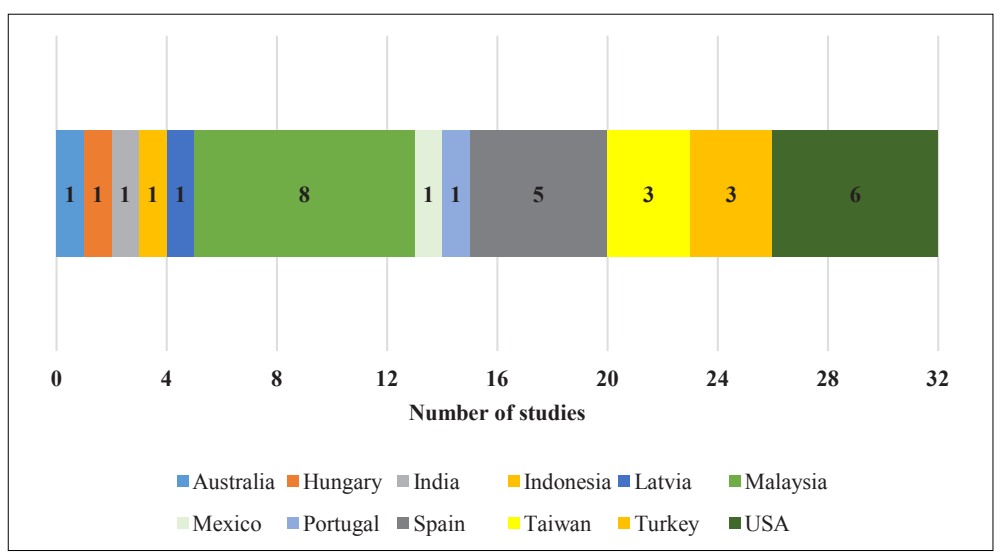

Fig. 4. The number of studies published by country.

contributing country, USA, were also supported by funds such as the National Science Foundation (NSF). Spanish researchers (de Ravé et al., 2016) acknowledge the support from the Spanish Ministry of Economy and Competitiveness. Finally, two of the three studies (Lee, 2019; Lee et al., 2019) from Taiwan were funded to deploy their studies from University department and the Ministry of Science and Technology, respectively. Conclusively, the leading contributing countries USA, Taiwan and Malaysia fund their researchers through grants.

Regarding the "Level of education", this category refers to the level of education of the participants in the experiments that the study of AR in spatial abilities' training was carried out. The majority of the studies (66\%) involved University students (Fig. 5). Preschool, Primary, Secondary and Technical education have very low percentage in the literature, around $3 \%$ or $6 \%$, proving a general tendency in the field of spatial skills' training to students of higher education (Fig. 5).

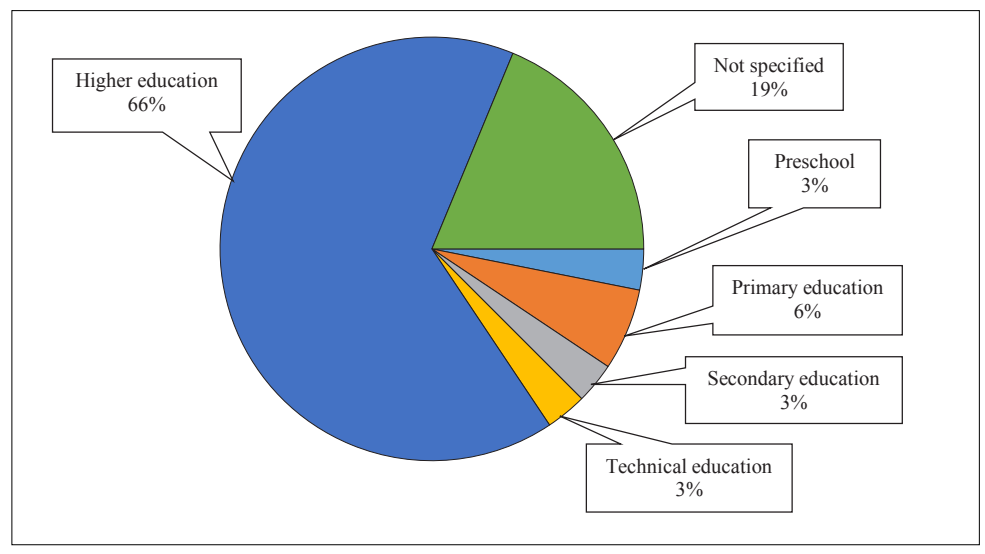

Fig. 5. Level of education applying AR on spatial skills' training. 


\section{Results and Discussion}

\subsection{Advantages of AR in Spatial Ability Training (RQ1)}

The first evaluation criterion analyzed in this systematic literature review deals with the reported advantages of AR in spatial abilities' training. After extracting the data from the studies, the identified advantages were arranged into three categories. The results of the reported advantages are presented in a descriptive manner as frequencies in Table 2.

Table 2

The advantages of AR in spatial abilities' training

\begin{tabular}{|c|c|c|c|}
\hline Categories & Sub-categories & Frequency & Sample research \\
\hline \multirow{11}{*}{$\begin{array}{l}\text { Learning } \\
\text { outcomes }\end{array}$} & Enhances spatial ability & 25 & Roca-González et al., 2017 \\
\hline & Increases students' understanding & 12 & Ali et al., 2018a \\
\hline & Enhances students' motivation & 5 & Medina Herrera et al., 2019 \\
\hline & Improves students' academic performance & 5 & Gün \& Atasoy, 2017 \\
\hline & Positive attitude towards the course & 4 & Martín-Gutiérrez et al., 2010 \\
\hline & Visualizes abstract concepts & 4 & Phon et al., 2019 \\
\hline & Reduces cognitive load & 3 & Lee, 2019 \\
\hline & $\begin{array}{l}\text { Students observe models from different pers- } \\
\text { pectives }\end{array}$ & 3 & $\begin{array}{l}\text { Gecu-Parmaksiz \& Delialioğlu, } \\
2018\end{array}$ \\
\hline & Enhances satisfaction & 1 & Gutiérrez et al., 2015 \\
\hline & Assists students in solving given problems & 1 & Kaur et al., 2018 \\
\hline & Students memorize better the learning material & 1 & Tuker, 2018 \\
\hline \multirow{12}{*}{$\begin{array}{l}\text { Pedagogical } \\
\text { affordances }\end{array}$} & Attracts students' interest & 12 & Medina Herrera et al., 2019 \\
\hline & $\begin{array}{l}\text { Students manipulate virtual objects in real en- } \\
\text { vironment }\end{array}$ & 8 & Omar et al., 2019 \\
\hline & Enhances enjoyability & 5 & Bell et al., 2017 \\
\hline & $\begin{array}{l}\text { Increases engagement in teaching and learning } \\
\text { process }\end{array}$ & 4 & Chen et al., 2011 \\
\hline & Interaction with the immersive environment & 4 & Figueiredo et al., 2014 \\
\hline & Promotes self-directed learning & 4 & Tuker, 2018 \\
\hline & Autonomous training & 3 & de Ravé et al., 2016 \\
\hline & Personalization of learning & 2 & Tumkor, 2018 \\
\hline & Allows students to be an active learner & 1 & Omar et al., 2019 \\
\hline & Develops collaborative work in students & 1 & Medina Herrera et al., 2019 \\
\hline & Learning by doing & 1 & Tuker, 2018 \\
\hline & Student centered learning & 1 & Roca-González et al., 2017 \\
\hline \multirow{2}{*}{$\begin{array}{l}\text { Technical } \\
\text { perspectives }\end{array}$} & Easy to use & 11 & Omar, Farzeeha, \& Mokhtar, 2018 \\
\hline & Cost effective & 8 & Martín-Gutiérrez et al., 2010 \\
\hline
\end{tabular}




\subsubsection{Learner Outcomes}

The advantages of AR in spatial abilities' training that are related to either spatial visualization or spatial perception or mental rotation are gathered under the learning outcomes of enhancing spatial ability. Most of the studies (25 out of 32) reported that AR technology in education leads to this learning outcome. Numerous studies (12 out of 32) have indicated that AR increases students' understanding. For instance, AREDApps (Omar, Ali, Nasir, \& Sunar, 2019) was developed as an alternative to help increase students' understanding, enhance visualization skills and attract students' interests in engineering drawing. Moreover, AR provides the ability to help students develop a deeper understanding (Phon et al., 2019).

The review findings also indicate that AR can enhance students' motivation, improve students' academic performance, enhance positive attitude and visualize abstract concepts. Students feel more motivated in class when these tools are implemented in pedagogical activities in the classroom (Medina Herrera et al., 2019). Students' motivation to the instructional activities can be increased due to the rich features of the learning environment (Tuker, 2018). Furthermore, the use of AR materials in the educational environment improves the students' academic achievement (Gün \& Atasoy, 2017). According to Martín-Gutiérrez et al. (2010), faculty members that participated in the validation study perceived a very positive and receptive attitude by students. With the use of 3D imagery, students can visualize the abstract concept (Ali et al., 2017a), which cannot be easily seen in a real-life setting (Phon et al., 2019).

Some researchers reported specific AR-related learning outcomes such as the reduction of cognitive load, the enhancement of satisfaction, the student observation from different perspectives, the provision of assistance to students for solving given problems and the better memorization of learning material. For example, Lee (2019) compared the scores of mental effort and mental load separately based on a pairedsample t-test, resulting in a significant difference in terms of mental effort and mental load between experimental and controls group. In another study, Gutiérrez et al. (2015) reported the great degree of satisfaction on the part of students when the AR technology is used.

\subsubsection{Pedagogical Affordances}

According to the pedagogical affordances of AR, the most prominent contributions are the attraction of students' interest, the manipulation of virtual objects in real environment and the enhancement of enjoyability. Most of the students show a great interest, expressing awe and revelation in their faces while exploring with the new tools until they found new purposes (Medina Herrera et al., 2019). Lee et al. (2019) concluded that the participants in the experimental group showed a great interest in using their AR training system. AR provides a platform for students to manipulate a virtual object freely from various perspectives, as they can use their bare hands to make manipulation (Phon et al., 2019). In addition to that, all of the students stated that the AR application made the classes more enjoyable (Gün \& Atasoy, 2017).

AR technology is valuable, engaging, and useful in the engineering design graphics domain, particularly when visualizing challenging models. Excitement and engagement 
could be easily observed in the participants during the exercise, although this could be attributed to the fact that many had never used or experienced AR technology before (Dorribo-Camba \& Contero, 2013).

On the other hand, the indications of self-directed and/or personalization of learning and autonomous training were reported in very few studies within the 32 reviewed research articles, and they all suggest that further study is warranted regarding potential benefits for development ability and confidence in spatial skills.

\subsubsection{Technical Perspectives}

The last part of Table 2 shows two advantages that could not be arranged to neither the learner's outcomes nor the pedagogical affordances. Omar et al. (2018) deployed an AR teaching and learning kit named AREDKit which is practical to be used in classrooms since it has low production cost. Furthermore, it has easy to use functions which can be operated using smartphones. Chandrasekera \& Yoonc's (2015) study intended to incorporate AR into the architectural curriculum, so they also chose to construct a costeffective and easy-to-use system. The AR system Dorribo-Camba \& Contero (2013) presented was low cost and easy to implement. In addition to the printed materials, only a computer with the proper software installed and a web camera were required.

\subsection{Limitations of AR in Spatial Ability Training (RQ2)}

Even though AR provides many advantages, researchers have reported some limitations imposed by this technology (Table 3 ). The most reported limitation is that the content is still poor. Some improvement actions may be incorporated into the application, such as expanding the content by increasing the amount and types of exercises and including self-evaluation tests (de Ravé et al., 2016).

Some other studies had the limitation of the small sample size (Chandrasekera \& Yoon, 2015; Kaur et al., 2018; Kim \& Irizarry, 2017). While the results of the studies are significant, a broader sampling to include more students of varying background could validate the research questions.

Another limitation was the absence of a control group. Therefore, the improvement of the posttest score of students may be made not only due to the AR learning experiment, but also by other variables. It is recommended to have a control group in the future investigation (Phon et al., 2019).

Additional training modules or help sections could be added to the App to familiarize the learner with the necessary know-how of the app usage (Kaur et al., 2018). A couple of studies reported the limitation that the results are specific to the location of the study (Buchori, Setyosari, Wayan Dasna, \& Ulfa, 2017; Chandrasekera \& Yoon, 2015), while two others stated that the participants had limited time for the training because many had their routine school homework to do and meetings to participate in (Bell et al., 2017; Lee, 2019).

The rest of the limitations involve application-related and technical problems. Future technological developments are expected to fix most of the current limitations. 
Table 3

The limitations in AR in spatial abilities' training

\begin{tabular}{|c|c|c|}
\hline Limitations & Frequency & Sample research \\
\hline Necessity for more content & 7 & de Ravé et al., 2016 \\
\hline Small sample size & 3 & Kaur et al., 2018 \\
\hline Control group missing & 2 & Phon et al., 2019 \\
\hline Help sections missing & 2 & Kaur et al., 2018 \\
\hline Country location specific results & 2 & Chandrasekera \& Yoon, 2015 \\
\hline The participants had limited time for the training & 2 & Lee, 2019 \\
\hline Data collection during very long periods of time & 1 & Medina Herrera et al., 2019 \\
\hline Focuses only on beginners & 1 & Lee, 2019 \\
\hline $\begin{array}{l}\text { Gender related differences in performance could not be examined } \\
\text { due to unequal gender ratio }\end{array}$ & 1 & $\begin{array}{l}\text { Veide, Strozheva, \& Dobelis, } \\
2014\end{array}$ \\
\hline $\begin{array}{l}\text { Limited financial resources limit a further development and wider } \\
\text { application of this technology in the education process }\end{array}$ & 1 & $\begin{array}{l}\text { Veide, Strozheva, \& Dobelis, } \\
2014\end{array}$ \\
\hline Needs a re-design in terms of pedagogical instructions & 1 & Kaur et al., 2018 \\
\hline Needs many environmental settings and pre-settings of the system & 1 & Lee, 2019 \\
\hline No experimental testing & 1 & Figueiredo et al., 2014 \\
\hline Relatively new technology & 1 & $\begin{array}{l}\text { Gecu-Parmaksiz \& } \\
\text { Delialioğlu, } 2018\end{array}$ \\
\hline Requires long-term training and practice to master & 1 & Lee, 2019 \\
\hline $\begin{array}{l}\text { The app was under continued development during the course of } \\
\text { this study }\end{array}$ & 1 & Bell et al., 2017 \\
\hline The application needs supportive printed material & 1 & $\begin{array}{l}\text { Buchori, Setyosari, Wayan } \\
\text { Dasna, \& Ulfa, } 2017\end{array}$ \\
\hline The end product must achieve certain qualities & 1 & Omar et al., 2018 \\
\hline
\end{tabular}

\subsection{Exploration of Incorporation of Adaptivity and Personalization in AR apps (RQ3)}

Table 4 shows ten AR teaching applications, which have been developed since 2010, all aiming to improve students' spatial skills and provide better perception of 3-dimensional shape of an object. The results show that the developers from 2010 until 2012 were using mainly desktop augmented. For instance, an augmented book called "AR-Dehaes", being designed to provide 3D virtual models, helps students to perform visualization tasks promoting the development of their spatial ability during a short remedial course (Martín-Gutiérrez et al., 2010). The "AR models" are the virtual models which can superimpose $3 \mathrm{D}$ graphics of typical geometries on real-time video and dynamically vary view perspective in real-time to be seen as real objects. The AR model was developed using the ARToolKitPlus library including all the geometrical features generally taught in engineering graphics courses or technical drawing courses (Chen et al., 2011). Both of these applications require programming knowledge in $\mathrm{C}++$ language using Brainstorm eStudio and ARToolKitPlus respectively in their development process, which can be a significant drawback. "AR enhanced exercise book" is another desktop approach presented in 2012 that aims to improve the spatial ability of freshman engineering students (Contero, Gomis, Naya, Albert, \& Martin-Gutierrez, 2012). 
Table 4

AR applications training spatial ability

\begin{tabular}{|c|c|c|c|c|c|c|}
\hline Article & Learning tool & $\begin{array}{l}\text { AR } \\
\text { approach }\end{array}$ & AR type & Software & Content & $\begin{array}{l}\text { Adap- } \\
\text { tivity }\end{array}$ \\
\hline $\begin{array}{l}\text { Martín-Gutiérrez } \\
\text { et al., } 2010\end{array}$ & $\begin{array}{l}\text { AR-Dehaes } \\
\text { augmented book }\end{array}$ & Desktop & Marker-based & Brainstorm eStudio & 3D models & No \\
\hline Chen et al., 2011 & AR models & Desktop & Marker-based & ARToolKitPlus & 3D models & No \\
\hline $\begin{array}{l}\text { Contero et al., } \\
2012\end{array}$ & $\begin{array}{l}\text { AR enhanced } \\
\text { exercise book }\end{array}$ & Desktop & Marker-based & not specified & 3D models & No \\
\hline $\begin{array}{l}\text { Figueiredo et al., } \\
2014\end{array}$ & EducHolo & Mobile & Marker-based & $\begin{array}{l}\text { AutoCAD } \\
\text { Augment }\end{array}$ & 3D models & No \\
\hline $\begin{array}{l}\text { de Ravé et al., } \\
2016\end{array}$ & DiedricAR & Mobile & Marker-based & $\begin{array}{l}\text { Unity 3D } \\
\text { Vuforia SDK }\end{array}$ & 3D models & No \\
\hline Omar et al., 2018 & AREDKit & $\begin{array}{l}\text { Not } \\
\text { specified }\end{array}$ & Not specified & $\begin{array}{l}\text { AutoDesk 3DS Max } \\
\text { Unity 3D } \\
\text { Android Studio }\end{array}$ & 3D models & No \\
\hline Kaur et al., 2018 & GeoSolvAR & Mobile & Marker-based & $\begin{array}{l}\text { Unity 3D } \\
\text { Vuforia SDK }\end{array}$ & 3D models & No \\
\hline Phon et al., 2019 & $\begin{array}{l}\text { ARScience } \\
\text { Magic Book }\end{array}$ & $\begin{array}{l}\text { Desktop / } \\
\text { Laptop }\end{array}$ & Marker-based & not specified & 3D models & No \\
\hline $\begin{array}{l}\text { Omar, Ali, } \\
\text { Mokhtar, et al., } \\
2019\end{array}$ & MAR & Mobile & Marker-based & $\begin{array}{l}\text { AutoDesk 3DS Max } \\
\text { Unity 3D } \\
\text { Android Studio }\end{array}$ & 3D models & No \\
\hline $\begin{array}{l}\text { Omar, Ali, Nasir, } \\
\text { et al., } 2019\end{array}$ & AREDApps & Mobile & Marker-based & $\begin{array}{l}\text { Unity 3D } \\
\text { Vuforia SDK } \\
\text { Android Studio }\end{array}$ & 3D models & No \\
\hline
\end{tabular}

Since 2014 , the developers started to use mobile AR, mainly due to the proliferation of mobile technology (such as mobile phones, tablets, wireless network etc.). The freedom degree of the user increases in mobile AR applications compared to desktop AR applications.

Figueiredo et al. (2014) presented the creation of a low-cost prototype, the "EducHolo", which enabled the visualization and interaction with holograms. Their aim was to provide a better perception of the model 3D shape improving the ability of making the $2 \mathrm{D}$ orthographic views and perspectives that the first year of mechanical engineer studied. They used Augment software that is free without requiring programming. The "DiedricAR" application allowed students to learn in autonomously way by using their own mobile devices that work as AR displays over training material (de Ravé et al., 2016). Other applications developed the last two years are: i) "AREDKit" developing to allow manipulation of 3D virtual models with the purpose to help students to perform visualization tasks during the process of teaching and learning (Omar et al., 2018), ii) "GeoSolvAR" focusing on middle school students for improving their visualization skills (Kaur et al., 2018), iii) “ARScience Magic Book” Learning System (AR-SMB) developing to facilitate students in learning science concept, and hence, enhancing their spatial visualization ability (Phon et al., 2019), iv) "MAR" and "AREDApps" being the most recent known approaches in the teaching and learning of orthographic projection (Omar, Ali, Mokhtar, et al., 2019; Omar, Ali, Nasir, et al., 2019). 
Apart from the "ARScience Magic Book" for which the authors did not clearly explain the platform they used to develop it, the rest five applications were all developed using Unity 3D software to create the AR environment. This is an object-oriented framework with graphic interface that can build applications for many different platforms including iOS and Android. Unlike other frameworks, Unity3D allows an easy handling of virtual models. Additionally, some of the applications used Autodesk 3D Studio Max as 3D modelling software to create and render 3D models and Android Studio as the official integrated development environment (IDE) for Google's Android operating system. Vuforia is also used as a good SDK (Software Development Kit) that provides functionalities for the development of AR applications on mobile using as targets or patterns, images or objects. For the development and deployment of the application to the mobile devices, Unity3D is used. Unity3D is a game engine that can be integrated with Vuforia allowing the development of AR applications.

Among all these teaching applications, it can be noted that the trend in the usage of AR approach is 3D models content. The justification for choosing three-dimensional model as the augmented objects is made based on the major trends and the effectiveness of learning using three-dimensional models towards improving spatial visualization skills.

Table 4 also illustrates that there is still no approach, desktop or mobile, that has included adaptivity or personalization processes. A personalized AR-system could possibly provide agent-customized training for students' learning performance enhancement. An agent-based infrastructure could support the customization of the spatial abilities assignments as triggered by the performance of the trainee. Another example of adaptive AR-system could be the user modelling, so that the contents and flow of the learning could be customized. On the basis of the reviewed literature, AR implementation has never been considered yet for this topic. There is a need for further research on the personalization aspect in a learning environment, which should meet the needs and interests of individual learners.

\subsection{Aspects of Spatial Abilities Having Been Evaluated Using AR (RQ4)}

The fourth research question investigates the aspects of spatial abilities that have been evaluated using AR. The assessment of spatial ability is critical as specific standardized tests offer a valuable piece of knowledge about specific spatial subcomponents. It is important for researchers or employers to know what aspect they want to evaluate, so that they select a test with strong reliability and validity evidence.

Currently, studies on spatial abilities follow two lines of research with respect to the definition of factors. The first one is the proposal of three factors: i) spatial perception; ii) spatial orientation or mental rotation, considered to be unique; and iii) spatial visualization. The second line is the proposal of two factors: i) spatial relation, or mental rotation; and ii) spatial visualization (Roca-González et al., 2017).

Various tests for measuring spatial ability are currently available, partly because there is no unitary definition of spatial ability; rather, spatial ability is often defined in 
terms of several subcomponents. A number of studies have been published on students' spatial skills and standardized tests to measure the level of achievement in different aspects of spatial ability.

As seen in Table 5, the Purdue Spatial Visualization Tests: Visualization of Rotations (PSVT:R) has been commonly used to predict students' success in spatial skills' training. PSVT was developed by Guay (1976) and consists of 36 questions. More specific, the test consists of three 12-item subtests entitled Developments, Rotations, and Views, respectively. The PSVT:R is an extended version of the subtest, Rotations, to measure the 3 -D mental rotation ability of individuals aged 13 or above in 20 minutes. The PSVT:R has 30 items consisting of 13 symmetrical and 17 nonsymmetrical 3-D objects that are drawn in a 2-D isometric format. In each item, the respondents' task is to mentally rotate an object in the same direction as indicated visually in the instructions, and then to select an answer from among five possible options (Maeda et al., 2013).

At the second place of the most frequent tests are the DAT:SR and MRT tests. Differential Aptitude Tests: Space Relations (DAT:SR) measures learner's ability to move from $2 \mathrm{D}$ to $3 \mathrm{D}$ world. It consists of 50 questions about paper folding. Vandenberg \& Kuse's (1978) Mental Rotation Test (MRT) was given to measure students' improvement in spatial skills. MRT is one of the most used tests that measure the spatial relations. Mental rotation is the perceptual process of visualizing an item at different angles in a three-dimensional world. The students compared objects depicted on a paper or monitor and find the identical ones. The original image and the identical ones are displayed at different rotations. There are 20 items in MRT, in each item, the left side consists of a target figure and the right side consists of four (or three in some revised versions) sample stimuli. The participant needs to choose the correct figure that represents the rotation of the target figure.

The Mental Cutting Test (MCT) measures the ability to visualize object cutting and was first developed for a university entrance examination in the USA, College Entrance Examination Board (CEEB) in 1939. The test consists of 25 items. For each problem on the exam, students are shown a criterion figure which is to be cut with an assumed plane. They must choose the correct resulting cross-section from among five alternatives.

Table 5

Standardized tests to measure spatial skills

\begin{tabular}{llc}
\hline Test & Frequency & Percentage \\
\hline Purdue Spatial Visualization Tests: Visualization of Rotations (PSVT:R) & 8 & $28,57 \%$ \\
Differential Aptitude Tests: Space Relations (DAT:SR) & 7 & $25,00 \%$ \\
Mental Rotation Test (MRT) & 7 & $25,00 \%$ \\
Mental Cutting Test (MCT) & 1 & $3,57 \%$ \\
Middle Grades Mathematics Project (MGMP) & 1 & $3,57 \%$ \\
Minnesota Paper Form Board Test (MPFBT) & 1 & $3,57 \%$ \\
Picture Rotation Test (PRT) & 1 & $3,57 \%$ \\
Spatial Perception Scale (SPS) & 1 & $3,57 \%$ \\
Spatial Orientation Test (SOT) & 0 & $0,00 \%$ \\
\hline
\end{tabular}


Middle Grades Mathematics Project (MGMP) and Minnesota Paper Form Board Test (MPFBT) have been used just from one study each one of them (Ali et al., 2018b; Gün \& Atasoy, 2017). This low usability is also observed in Picture Rotation Test (PRT) and Spatial Perception Scale (SPS) respectively. The first one measures the rotation skills of pre-and-early primary school children (ages from four to six) (Quaiser-Pohl, 2003) and the second one measures the visualization \& orientation skills of six-year-old children (Gecu-Parmaksiz \& Delialioğlu, 2018) but this mainly due to the preschool domain which is not among the target groups of AR spatial skills training.

The last one named Spatial Orientation Test (SOT) was not found in any of the selected studies. This is due to the fact that the majority of authors and researchers recognize two factors: mental rotation; and visualization. They don't really include the third category: spatial orientation as well as the specific instrument for measuring it.

\subsection{Evaluation Methods Considered for AR Applications in Educational Scenarios (RQ5)}

The fifth research question examines the methodology in terms of AR applications. It is very important for the researchers to identify the correct strategy for their study so that the results provide valid information.

It was found that the most preferred research sample size in educational AR in Spatial Ability training studies is between 11-50 (40,6\%) (Table 6). This sample size is followed by sample size of $51-100(31,3 \%)$ and both of them sum up to $72 \%$. The sample size of above $100(9,4 \%)$ is coming at the third place, $3,1 \%$ of the studies were conducted with 1-10 participants whereas $15,6 \%$ of the studies did not provide any sample size.

It was found that the most common research method in educational AR in Spatial Ability training studies is mixed $(40,6 \%)$ and the least common is qualitative $(12,5 \%)$ (Table 7$)$. Other common research method is quantitative $(28,1 \%)$, whereas $18,8 \%$ of the studies did not provide the applied research method.

The results show that the most common data collection tool is post-test $(30,9 \%)$, and among the least common employed data collection tool are case study and interview $(2,9 \%$ each) (Table 8$)$. At the same category of the least common collection tools, there are the observation, the survey, long-term test and instructor's evaluation which are

Table 6

Distribution of research sample size

\begin{tabular}{lcr}
\hline Sample Size & Frequency & \multicolumn{1}{c}{$\%$} \\
\hline between 1-10 & 1 & $3,1 \%$ \\
between 11-50 & 13 & $40,6 \%$ \\
between $51-100$ & 10 & $31,3 \%$ \\
above 100 & 3 & $9,4 \%$ \\
not specified & 5 & $15,6 \%$ \\
\hline
\end{tabular}


Table 7

Research methods applied

\begin{tabular}{lcl}
\hline Research Method & Frequency & $\%$ \\
\hline Quantitative & 9 & $28,1 \%$ \\
Qualitative & 4 & $12,5 \%$ \\
Mixed & 13 & $40,6 \%$ \\
Not Specified & 6 & $18,8 \%$ \\
\hline
\end{tabular}

Table 8

Data collection method

\begin{tabular}{lcr}
\hline Data Collection Tool & Frequency & $\%$ \\
\hline Case Study & 2 & $2,9 \%$ \\
Interview & 2 & $2,9 \%$ \\
Post-Test & 21 & $30,9 \%$ \\
Pre-Test & 19 & $27,5 \%$ \\
Questionnaire & 13 & $18,8 \%$ \\
Other & 4 & $5,9 \%$ \\
Not Specified & 7 & $10,3 \%$ \\
\hline
\end{tabular}

all included in the other category. Other data collection tools are pre-tests $(27,5 \%)$ and questionnaires $(18,8 \%)$. It should be mentioned that in 19 studies, pre-test method was applied, and in all of them, post-test method was also applied in order to compare the learning achievement.

\section{A Novel Adaptive AR-SAT Framework}

Based on the literature review, presented in the current research, we showed that there are a few AR applications (Chen et al., 2011; Contero, Gomis, Naya, Albert, \& MartinGutierrez, 2012; Martín-Gutiérrez et al., 2010), developed to help students improve their spatial skills using a desktop approach while some other applications (Figueiredo et al., 2014; de Ravé et al., 2016; Kaur et al., 2018; Omar et al., 2018; Phon et al., 2019) used a mobile approach. All of the existing AR applications were developed according to the existing programming and/or technology knowledge of the researchers and were not based on a specific framework. Furthermore, intelligent tutoring systems (ITSs) (Troussas et al., 2020), offering more independence to students during the training sessions, have been implemented in different educational fields and could be combined with AR in order to provide next-generation advanced educational software. Intelligent AR tutoring systems should provide a personalized interface which is currently absent. The design and implementation of ITSs using AR involves many software and hardware challenges and future developers should be guided through this proposed framework. 
The literature reveals that few studies have focused on the potential of AR in spatial abilities training. As such, the findings of this literature review motivated the development of a framework for applying AR for Spatial Abilities Training (AR-SAT). The major difference between the proposed framework in this study and the conventional methods is that the educational process is adaptive through mobile-assisted AR.

In order to achieve the study goal, a framework has been developed reflecting the typical spatial abilities training, comprising of three modules which are: i) the Domain Knowledge Model (DKM); ii) the Student Model (SM); and iii) the User Interface Model (UIM) (Fig. 6).

The Domain Knowledge Model uses 3D models content. The effectiveness of learning technical drawing using three-dimensional models towards improving spatial visualization skills is a parameter derived from Table 4 in the third research question. The AR application uses objects of 3D models designed in a software appropriate for 3D modeling, animation and rendering such as Autodesk 3ds Max and it will be used for the creation of a $3 \mathrm{D}$ object library.

The purpose of the Student Model is to construct the users' profile. This module uses questionnaires and tests to generate users' cumulative profile. As a result, the users will navigate through the AR application and access content based on their profile. Student modelling could also implement an agent-based infrastructure in order to support the customization of the spatial abilities assignments as triggered by the performance of the trainee.

Finally, the User Interface Model which, taking into consideration the results of the third research question, adopts the video game creation platform named Unity3D for the development and deployment of the application to the mobile devices. It can superpose the virtual onto reality and realizes human-computer interaction. Unity3D is a game engine that can be integrated with Vuforia SDK, an AR software development kit which provides functionalities for the development of AR applications on mobile using as targets images or objects. Finally, Android Studio is interfaced with Unity 3D to build the application for Android environment.

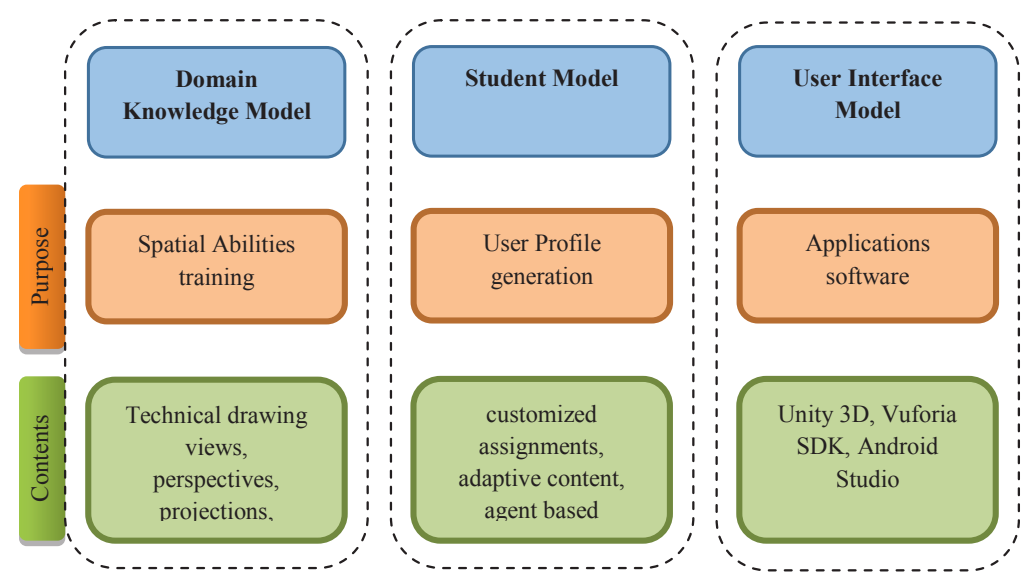

Fig. 6. A framework for using mobile based adaptive AR-SAT. 


\section{Conclusion}

In this research, a comprehensive review regarding AR in spatial ability training has been conducted and the technologies, application areas and future research directions have been identified. General reviews of AR applications focusing on education have been made; however, there is absence of systematic literature review when it comes to the use of AR in spatial ability training. The identified research gaps are: i) the absence of commercial AR applications developed for the training of the spatial abilities; ii) the absence of adaptivity of the systems in existing literature; and iii) the need for developing a novel framework to focus on the design elements of an AR application.

Trends of AR are: i) the development of mobile (smartphones and tablets) AR applications; ii) the use of Unity3D as the creation platform; iii) the use of Vuforia as the AR software development kit; and iv) 3ds Max as 3D modelling software. Spatial ability is very important in engineering education and AR technology can suggest areas in which to invest new research. The review offers new insight to researchers as it points toward unexplored regions of engineering education and urges educators to incorporate AR into their teaching methods.

Based on the review of 32 studies, we found an increase in the research studies during the last three years, from 2017 to 2019. The primary education level of the target group is higher education and more specifically first year engineering students as the development of spatial skills is important for their future studies and career.

AR offers unique advantages to the learners, such as the improvement of their spatial ability, the better understanding of the topic and gradually the improved academic performance and motivation. When it comes to pedagogical contributions, AR is shown to attract students' interest, enhances enjoyability and increases their engagement in the teaching and learning process.

The development of AR applications is transitioning from desktop-based to mobile ones, especially with the global ease of use of mobile phones and tablets. The majority of AR applications, reviewed in this study, are marker-based and their content is $3 \mathrm{D}$ models as $3 \mathrm{D}$ modelling is shown to be very effective when it comes to improving spatial visualization skills. However, none of them considered the inclusion of combined adaptivity or personalization processes, pointing out the future research interest.

To get a thorough review of the topic for this study, we accumulated articles published between 2010 and 2019. A total of 32 journal articles, conference papers and book chapters, which are relevant to our topic, were selected to be evaluated by inclusion criteria. Our first priority was the journal articles ( 21 selected), and we also selected the most recent and relevant conference papers ( 8 selected) and book chapters (3 selected). Future researchers may wish to amplify this research by exploring all the conference papers, Master theses and $\mathrm{PhD}$ dissertations and expand the literature source to other electronic databases (other than Scopus which was used in this research, e.g. Google Scholar, Web of Science) as well, in order to form a wider view of the topic. 


\section{Future Research Directions}

This review has identified a critical issue in the existing literature, namely the lack of combined adaptivity or personalization processes, pointing out the future research interest. Some of the advantages of AR in spatial skills' training is the autonomous and self-directed training, giving prominence to personalization as the necessary parameter to be examined for the flexibility of the developed system according to the user requirements. Another challenge for future work is the gender differences in spatial thinking. It is a topic with controversial result as some researchers conclude in the existence of gender gaps in spatial ability while some other did not find any gender differences when it comes for cognitive abilities.

\section{References}

Akçayır, M., \& Akçayır, G. (2017). Advantages and challenges associated with augmented reality for education: A systematic review of the literature. Educational Research Review, 20, 1-11. https://doi.org/10.1016/j.edurev.2016.11.002

Ali, D. F., Omar, M., Boon, Y., Ahmad, J., Wahid, N. H. A., Noordin, M. K., ... Ibrahim, M. A. (2018a). The Use of Augmented Reality Learning Environment in Enhancing Students' Mental Rotation Skills. Advanced Science Letters, 24(5), 3705-3708. https : //doi .org/10.1166/asl . 2018.11470

Ali, D. F., Omar, M., Ibrahim, N. H., Surif, J., Ali, M., \& Ismail, S. (2017a). Overcoming the problems faced by student's in learning engineering drawing with the implementation of augmented reality learning environment. Man in India, 97(17), 147-159.

Ali, D. F., Omar, M., Mohamed, H., Zaid, N. M., Mokhtar, M., \& Abdullah, A. H. (2018b). Application of Augmented Reality Learning Environment in Enhancing Students' Mental Cutting Skills and Mental Folding Skills. Advanced Science Letters, 24(5), 3701-3704. https : //doi .org/10.1166/as1.2018.11469

Ali, D. F., Omar, M., Mokhtar, M., Suhairom, N., Abdullah, A. H., \& Halim, N. D. A. (2017b). A review on augmented reality application in engineering drawing classrooms. Man in India, 97(19), 195-204. Retrieved from https://www.researchgate.net/publication/320878073

Arslan, A. R., \& Dazkir, S. (2017). Technical Drafting and Mental Visualization in Interior Architecture Education. International Journal for the Scholarship of Teaching and Learning, 11(2). https://doi.org/10.20429/ijsotl.2017.110215

Azuma, R., Baillot, Y., Behringer, R., Feiner, S., Julier, S., \& MacIntyre, B. (2001). Recent advances in augmented reality. IEEE Computer Graphics and Applications, 21(6), 34-47. https://doi.org/10.1109/38.963459

Bacca, J., Baldiris, S., Fabregat, R., Graf, S., \& Kinshuk. (2014). Augmented reality trends in education: A systematic review of research and applications. Educational Technology and Society, 17(4), 133-149.

Bell, J., Hinds, T., Walton, P., Cugini, C., Cheng, C., Freer, D., ... Klautke, H. (2017, June 24). A Study of Augmented Reality for the Development of Spatial Reasoning Ability. https://doi.org/10.18260/1-2--27831

Buchori, A., Setyosari, P., Wayan Dasna, I., \& Ulfa, S. (2017). Mobile augmented reality media design with waterfall model for learning geometry in college. International Journal of Applied Engineering Research, 12(13), 3773-3780.

Chandrasekera, T., \& Yoon, S. Y. (2015). Adopting augmented reality in design communication: Focusing on improving spatial abilities. International Journal of Architectonic, Spatial, and Environmental Design, 9(1), 1-14. https://doi.org/10.18848/2325-1662/CGP/v09i01/38384

Chen, Y. C., Chi, H. L., Hung, W. H., \& Kang, S. C. (2011). Use of tangible and augmented reality models in engineering graphics courses. Journal of Professional Issues in Engineering Education and Practice, 137(4), 267-276. https://doi.org/10.1061/(ASCE) EI.1943-5541.0000078

Contero, M., Gomis, J. M., Naya, F., Albert, F., \& Martin-Gutierrez, J. (2012). Development of an augmented reality based remedial course to improve the spatial ability of engineering students. Proceedings - Frontiers in Education Conference, FIE. https://doi.org/10.1109/FIE. 2012.6462312 
de Ravé, E. G., Jiménez-Hornero, F. J., Ariza-Villaverde, A. B., \& Taguas-Ruiz, J. (2016). DiedricAR: a mobile augmented reality system designed for the ubiquitous descriptive geometry learning. Multimedia Tools and Applications, 75(16), 9641-9663. https ://doi .org/10.1007/s11042-016-3384-4

Diao, P. H., \& Shih, N. J. (2019). Trends and research issues of augmented reality studies in architectural and civil engineering education-A review of academic journal publications. Applied Sciences (Switzerland), 9(9). https://doi.org/10.3390/app9091840

Dorribo-Camba, J., \& Contero, M. (2013). Incorporating augmented reality content in engineering design graphics materials. Proceedings - Frontiers in Education Conference, FIE, 35-40. https://doi.org/10.1109/FIE. 2013.6684784

Figueiredo, M., Cardoso, P. J. S., Rodrigues, J. M. F., \& Alves, R. (2014). Learning Technical Drawing with Augmented Reality and Holograms. Recent Advances in Educational Technologies and Methodologies, $1-20$.

Garzón, J., Pavón, J., \& Baldiris, S. (2019). Systematic review and meta-analysis of augmented reality in educational settings. Virtual Reality, 23(4), 447-459. https : //doi .org/10.1007/s10055-019-00379-9

Gecu-Parmaksiz, Z., \& Delialioğlu, Ö. (2018). The effect of augmented reality activities on improving preschool children's spatial skills. Interactive Learning Environments, 0(0), 1-14. https://doi.org/10.1080/10494820.2018.1546747

Goktas, Y., Arpacik, O., Kucuk, S., Yildirim, G., Aydemir, M., Reisoğlu, İ., \& Telli, E. (2012). Educational Technology Research Trends in Turkey: A Content Analysis of the 2000-2009 Decade.

Guay, R. (1976). Purdue spatial visualization test. [West Layfette, Ind.]: Purdue University.

Gün, E. T., \& Atasoy, B. (2017). The effects of augmented reality on elementary school students' spatial ability and academic achievement. Egitim ve Bilim, 42(191), 31-51. https://doi.org/10.15390/EB.2017.7140

Gutiérrez, J. M., Domínguez, M. G., \& González, C. R. (2015). Using 3D virtual technologies to train spatial skills in engineering. International Journal of Engineering Education, 31(1), 323-334.

Huerta, O., Kus, A., Unver, E., Arslan, R., Dawood, M., Kofoğlu, M., \& Ivanov, V. (2019). A design-based approach to enhancing technical drawing skills in design and engineering education using VR and AR tools. VISIGRAPP 2019 - Proceedings of the 14th International Joint Conference on Computer Vision, Imaging and Computer Graphics Theory and Applications, 3(March), 306-313. https://doi.org/10.5220/0007566003060313

Jian, Z. (2011). Teaching of Engineering Drawing in the 21st century. 2011 Second International Conference on Mechanic Automation and Control Engineering, 1713-1715. https://doi.org/10.1109/MACE. 2011.5987287

Karakus, M., Ersozlu, A., \& Clark, A. (2019). Augmented Reality Research in Education: A Bibliometric Study. Eurasia Journal of Mathematics, Science and Technology Education, 15(10). https://doi.org/10.29333/ejmste/103904

Kaur, N., Pathan, R., Khwaja, U., \& Murthy, S. (2018). GeoSolvAR: Augmented reality based solution for visualizing 3D Solids. Proceedings - IEEE 18th International Conference on Advanced Learning Technologies, ICALT 2018, 372-376. https ://doi .org/10.1109/ICALT.2018.00093

Khine, M. S. (2017). Visual-spatial Ability in STEM Education. In Visual-spatial Ability in STEM Education. https://doi.org/10.1007/978-3-319-44385-0

Kim, J., \& Irizarry, J. (2017). Assessing the effectiveness of augmented reality on the spatial skills of postsecondary construction management students in the U.S. ISARC 2017 - Proceedings of the 34th International Symposium on Automation and Robotics in Construction, (August), 173-180. https://doi.org/10.22260/isarc2017/0023

Kitchenham, B. (2004). Procedures for Performing Systematic Literature Reviews. Joint Technical Report, Keele University TR/SE-0401 and NICTA TR-0400011T.1, 33.

Kitchenham, B., K., \& Charters, S. (2007). Guidelines for performing Systematic Literature Reviews in Software Engineering. 2.

Lee, I. J. (2019). Using augmented reality to train students to visualize three-dimensional drawings of mortisetenon joints in furniture carpentry. Interactive Learning Environments, 0(0), 1-15. https://doi.org/10.1080/10494820.2019.1572629

Lee, I. J., Hsu, T. C., Chen, T. L., \& Zheng, M. C. (2019). The application of ar technology to spatial skills learning in carpentry training. International Journal of Information and Education Technology, 9(1), 5660. https://doi.org/10.18178/ijiet.2019.9.1.1173

Lohman, D. F. (1996). Spatial ability and g. In: Human abilities: Their nature and measurement. (pp. 97-116). Hillsdale, NJ, US: Lawrence Erlbaum Associates, Inc. 
Maeda, Y., Yoon, S. Y., Kim-Kang, G., \& Imbrie, P. K. (2013). Psychometric properties of the revised PSVT:R for measuring First Year Engineering students' spatial ability. International Journal of Engineering Education, 29(3), 763-776.

Marner, M., Smith, R., Porter, S., Broecker, M., Close, B., \& Thomas, B. (2011). Large Scale Spatial Augmented Reality for Design and Prototyping. https://doi .org/10.1007/978-1-4614-0064-6_10

Martín-Gutiérrez, J., Luís Saorín, J., Contero, M., Alcañiz, M., Pérez-López, D. C., \& Ortega, M. (2010). Design and validation of an augmented book for spatial abilities development in engineering students. Computers and Graphics (Pergamon), 34(1), 77-91. https://doi.org/10.1016/j.cag.2009.11.003

Medina Herrera, L., Castro Pérez, J., \& Juárez Ordóñez, S. (2019). Developing spatial mathematical skills through 3D tools: augmented reality, virtual environments and 3D printing. International Journal on Interactive Design and Manufacturing (IJIDeM), 13(4), 1385-1399. https://doi.org/10.1007/s12008-019-00595-2

Omar, M., \& Ali, D. F. (2018). Enhancing students' mental rotation skills and 3-dimensional development skills using augmented reality learning environment. Journal of Fundamental and Applied Sciences, 10(1S)(May), 1053-1067. https://doi.org/10.4314/jfas.v10i1s.77

Omar, M., Ali, D. F., Mokhtar, M., Zaid, N. M., Jambari, H., \& Ibrahim, N. H. (2019). Effects of Mobile Augmented Reality (MAR) towards Students' Visualization Skills when Learning Orthographic Projection. International Journal of Emerging Technologies in Learning (IJET), 14(20), 106. https://doi.org/10.3991/ijet.v14i20.11463

Omar, M., Ali, D. F., Nasir, A. N., \& Sunar, M. S. (2019). AREDApps: Integrating mobile augmented reality in orthographic projection teaching and learning. International Journal of Recent Technology and Engineering, 8(1C2), 821-825.

Omar, M., Farzeeha, D., \& Mokhtar, M. (2018). Using Aredkit to Improve Spatial Visualization Skills for Using Aredkit to Improve Spatial Visualization. (November).

Pellas, N., \& Kazanidis, I. (2019). Developing and assessing augmented reality applications for mathematics with trainee instructional media designers: An exploratory study on user experience. Journal of Universal Computer Science, 25(5), 489-514.

Phon, D. N. A. L. E., Rahman, M. H. A., Utama, N. I., Ali, M. B., Halim, N. D. A., \& Kasim, S. (2019). The effect of augmented reality on spatial visualization ability of elementary school student. International Journal on Advanced Science, Engineering and Information Technology, 9(2), 624-629. https://doi.org/10.18517/ijaseit.8.5.4971

Quaiser-Pohl, C. (2003). The Mental Cutting Test "Schnitte" and the Picture Rotation Test-Two New Measures to Assess Spatial Ability. International Journal of Testing, 3(3), 219-231.

https://doi.org/10.1207/S15327574IJT0303_2

Roca-González, C., Martin-Gutierrez, J., García-Dominguez, M., \& Carrodeguas, M. del C. M. (2017). Virtual technologies to develop visual-spatial ability in engineering students. Eurasia Journal of Mathematics, Science and Technology Education, 13(2), 441-468. https://doi.org/10.12973/eurasia.2017.00625a

Serdar, T., Aziz, E. S. S., Esche, S. K., \& Chassapis, C. (2013). Integration of augmented reality into the CAD process. ASEE Annual Conference and Exposition, Conference Proceedings.

Sorby, S. (2007). Developing 3D spatial skills for engineering students. Australasian Journal of Engineering Education, 13,1-11. https://doi.org/10.1080/22054952.2007.11463998

Troussas C., Krouska A., Sgouropoulou C. (2020) Dynamic Detection of Learning Modalities Using Fuzzy Logic in Students' Interaction Activities. In: Kumar V., Troussas C. (eds) Intelligent Tutoring Systems. ITS 2020. Lecture Notes in Computer Science, vol 12149. Springer, Cham

Tuker, C. (2018). Training Spatial Skills with Virtual Reality and Augmented Reality. In N. Lee (Ed.), Encyclopedia of Computer Graphics and Games (pp. 1-9).

https://doi.org/10.1007/978-3-319-08234-9_173-1

Tumkor, S. (2018). Personalization of engineering education with the mixed reality mobile applications. Computer Applications in Engineering Education, 26(5), 1734-1741.

https://doi.org/10.1002/cae.21942

Vandenberg, S. G., \& Kuse, A. R. (1978). Mental rotations, a group test of three-dimensional spatial visualization. Perceptual and Motor Skills, 47(2), 599-604. https : //doi .org/10.2466/pms .1978.47.2.599

Veide, Z., Strozheva, V., \& Dobelis, M. (2014). Application of Augmented Reality for teaching Descriptive Geometry and Engineering Graphics Course to First-Year Students. Joint International Conference on Engineering Education \& International Conference on Information Technology, 158-164.

Voronina, M., Tretyakova, Z., Krivonozhkina, E., Buslaev, S., \& Sidorenko, G. (2019). Augmented Reality in Teaching Descriptive Geometry, Engineering and Computer Graphics - Systematic Review and Results of 
the Russian Teachers' Experience. Eurasia Journal of Mathematics, Science and Technology Education, 15(12). https://doi.org/10.29333/ejmste/113503

White, G., Cabrera, C., Palade, A., \& Clarke, S. (2019). Augmented reality in IoT. Lecture Notes in Computer Science (Including Subseries Lecture Notes in Artificial Intelligence and Lecture Notes in Bioinformatics), 11434 LNCS, 149-160. https : //doi .org/10.1007/978-3-030-17642-6_13

Yilmaz, R. M. (2018). Augmented Reality Trends in Education between 2016 and 2017 Years. State of the Art Virtual Reality and Augmented Reality Knowhow. https ://doi .org/10.5772/intechopen.74943

C. Papakostas is a Ph.D. Student in the Department of Informatics and Computer Engineering, University of West Attica, Greece. He has received a M.Sc. degree in Electrical and Computer Engineering and a B.Eng. from the Department of Electrical and Computer Engineering, Democritus University of Thrace, Greece. His current research interests are in the areas of augmented reality, learning technology applications and adaptive systems.

C. Troussas is Postdoctoral Researcher in the Department of Informatics and Computer Engineering, University of West Attica, Greece. He has received a Ph.D. Degree in Informatics, a M.Sc. degree in "Advanced Informatics and Computing Systems" and a B.Sc. degree in Informatics from the Department of Informatics, University of Piraeus, Greece. He has published a significant number of articles in international conferences, books and journals. His current research interests are in the areas of personalized software engineering, adaptive HCI, multi-agent systems and artificial intelligence in education.

A. Krouska is a Postdoctoral Researcher in the Department of Informatics and Computer Engineering, University of West Attica, Greece. She has received a Ph.D. Degree and a B.Sc. degree in Informatics from the Department of Informatics, University of Piraeus, Greece, as well as a M.Sc. degree in "Information Systems" from Athens University of Economics and Business, Greece. She has published a significant number of articles in international conferences, books and journals. Her research interests include social networking services, learning analytics, user modeling and artificial intelligence in education.

C. Sgouropoulou is Professor in the Department of Informatics and Computer Engineering, University of West Attica, Greece. She has received a Ph.D. Degree in Electrical and Computer Engineering and a B.Eng. from the Department of Electrical and Computer Engineering, National Technical University of Athens, Greece. She has published a significant number of articles in international conferences, books and journals. Her research interests are in the areas of software engineering, artificial intelligence in education, student modelling and quality assurance in education. 


\section{Appendix A. Data extraction form}

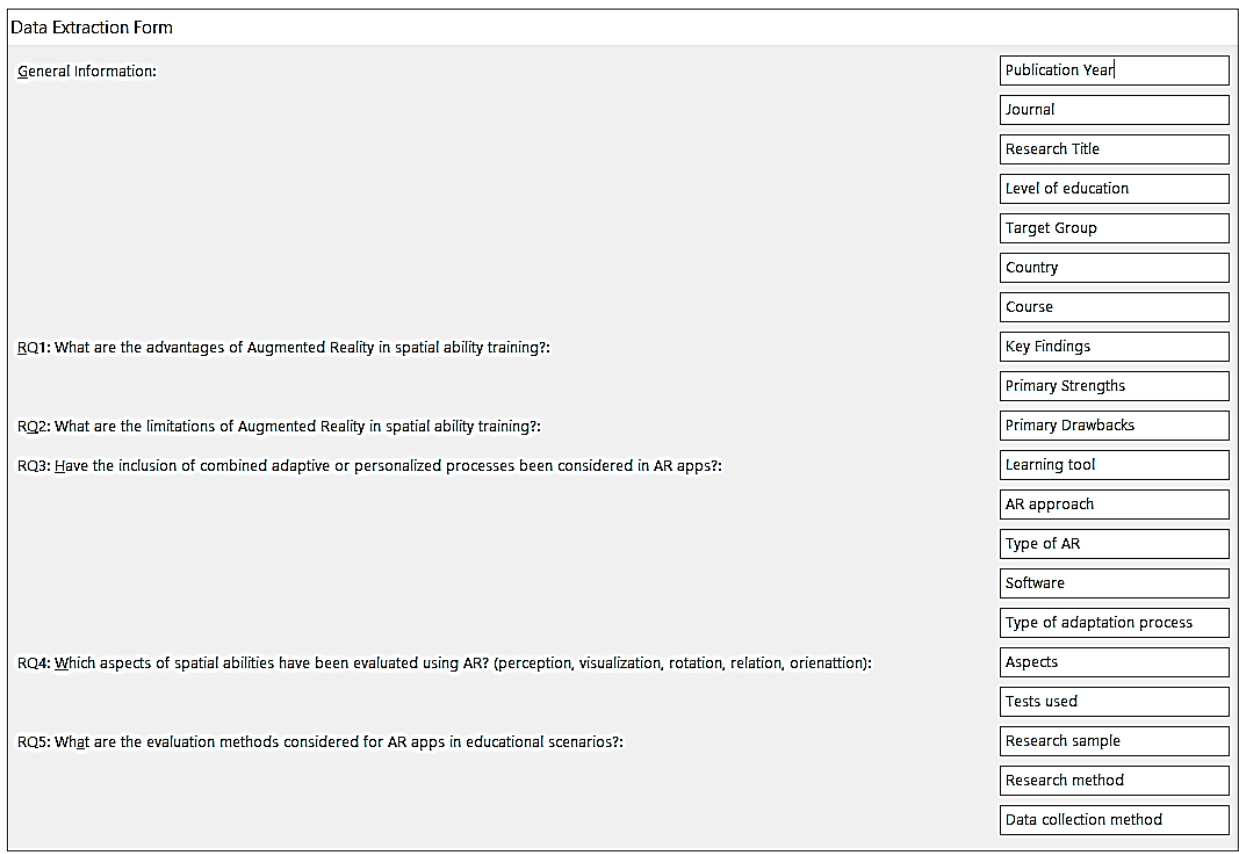

